\title{
COMMENTS ON "TRENDS TOWARD MECHANIZATION OF FOREST FIRE CONTROL"
}

(Ed. Note: Mr. P. McEwen, District Forester of the Ontario Forestry Branch, at Sudbury, made the following comments on Mr. Roy Headley's paper on "Trends toward mechanization of Forest Fire Control.")

\section{P. MCEWEN}

T IS amazing to hear of the extent to which mechanized equipment is being used in the United States Forest Service as outlined in Mr. Roy Headley's paper and one cannot but feel that we in Canada are lagging far behind in this method of fire control.

As Mr. Headley points out the use of heavy equipment, such as bulldozers, brush-busters and large trucks and trailers, depends on suitable roads to transport it quickly to the scene of action. One of our first problems would be to construct such roads or re-build the many miles of old tote roads in cut over areas now grown up and with their bridges rotted away. There are many hundreds of miles of these in sand and gravel plain areas which could be easily and quickly rehabilitated by the use of bulldozers. This work has been too long neglected and roads over which trucks can travel are the prime basis of fire protection. As Mr. Headley points out, mechanized equipment is heavy and roads are first needed to transport it. It is for the purpose of road building for a start, I think in which we could best use bulldozers. When roads have been established the use of other heavy equipment would naturally follow.

Another interesting development is the Bosworth Trencher. From reports of its use it appears to be a very efficient machine in assisting to give quicker control on the fire line. It is gratifying to learn that we are to be supplied with one of these machines in the Sudbury District for next summer and it is hoped we shall be able to give some definite account of its efficiency and possibilities by the next Annual Meeting.

It is to be noted that Mr. Headley states "Transportation is the true role of aircraft in fire control." This strikes me as being particularly apt and it behooves us to bend every effort in completing our tower detection system so that aircraft can be applied to its chief use. In our country where lakes abound, aeroplanes play a major part in fire control and the matter of their use and development for fire fighting should be kept in mind. The methods 
mentioned of dropping equipment and supplies to crews by parachute is very interesting and worthy of trial here in areas where lakes are few and scattered.

While on the subject of mechanical equipment it might be in order to mention two things that have developed in Ontario recently. One is a method of repairing linen fire hose by vulcanizing rubber over a patch or splice as the case may be. Many thousand feet of otherwise useless hose has been brought back into service and now all the districts in Ontario have been supplied with the equipment for doing the work.

The other is the development of a new forest fire pump by Mr. R. N. Johnston of the Ontario service. It is a very light compact unit combining good volume with high pressure and with a release valve feature which allows "kinking" the hose and shutting off the water output without in any way interfering with the action of the pump.

Mr. Headley wisely reminds us that "In the development of power driven tools, it is necessary to maintain our sense of balance." He has given us something to aim at but it would be well to bear in mind that in the development of fire control gadgets they should be well tried out and be capable of doing the job better than tools we already have.

Here is something we need and something mechanically minded readers can work on-a simple, practical machine that will "fold" hose as quickly as it can now be wound in a roll by the hose winders now in use. 